\title{
Vulneráveis ou vítimas? A experiência das redes de luta antimanicomial em Belo Ho- rizonte e a construção relacional de biopotências ${ }^{1}$
}

\author{
Lucas Henrique Nigri Veloso ${ }^{2}$ \\ Ângela Cristina Salgueiro Marques ${ }^{3}$
}

\begin{abstract}
Resumo: O presente artigo procura apresentar uma reflexão em duas frentes acerca dos modos de existência, vulnerabilidades e resistências que atravessam as experiências, interações e processos comunicativos de sujeitos e sujeitas em sofrimento mental no contexto da cidade de Belo Horizonte (MG). Primeiramente, a noção de vulnerabilidades é contraposta à ideia de vítima passiva, destacando-se o seu enraizamento nos conflitos sociais e na construção relacional da autonomia, à luz dos modos de expressão política do coletivo Associação dos Usuários de Saúde Mental de Minas Gerais (ASSUSAM-MG). Em um segundo momento, procura-se verificar em que sentido vulnerabilidades atuam na criação e invenção de narrativas, corporeidades, redes de aliança e modos de autodeterminação político-expressivas que emergem no contexto de luta antimanicomial, possibilitado pela Associação.
\end{abstract}

Palavras-chave: vulnerabilidade; vítima; sofrimento mental; biopotência; comum.

\begin{abstract}
This article aims to present a reflection on two fronts about the modes of existence, vulnerabilities and resistances that cross the experiences, interactions and communicative processes of subjects in mental suffering in the context of the city of Belo Horizonte (MG). Firstly, the notion of vulnerabilities is opposed to the idea of a passive victim, emphasizing its rootedness in social conflicts and the relational construction of autonomy in light of the modes of expression and communication of collectives such as the Mental Health Users Association of Minas Gerais (ASSUSAM-MG). Secondly, we seek to show the vulnerabilities role played in the creation and invention of narratives, bodies, networks of alliance and modes of political-expressive self-determination that emerge in the context of the anti-asylum struggle made possible by this Association.
\end{abstract}

Keywords: vulnerability; victim; mental suffering; biopotency; common.

1 A realização da pesquisa da qual se origina este artigo recebeu apoio do CNPq e da Fapemig.

2 Bacharel em Ciências Sociais pela Universidade Federal de Minas Gerais e Mestrando em Comunicação Social pelo PPGCOM da mesma instituição. E-mail: <lucasnveloso@ gmail.com>.

3 Doutora em Comunicação pela UFMG. Professora do Programa de Pós-Graduação em Comunicação da UFMG. E-mail: <angelasalgueiro@gmail.com>. 


\section{Introdução}

Os discursos e práticas de "governamentalidade" [1] dos Estados modernos são frequentemente alimentados por um entendimento de que as vulnerabilidades humanas, corpóreas e mentais, devem ser geridas, controladas e/ou eliminadas a fim de garantir uma pretensa funcionalidade e eficiência de seus sistemas sociais, econômicos e políticos. Não obstante, em contextos de crise econômica e política, o enquadramento que define a sociedade como um organismo que deve se tornar eficiente, funcional e invulnerável nos parece legitimar que diversas entidades que atentam contra sua (des)ordem não sejam dignas de uma vida passível de se viver (BUTLER, 2004). Em contrapartida, danos e injúrias que são exercidos sobre sujeitos mais vulneráveis que outros, mesmo em contextos em que legislações os definem como uma questão de resposanbilidade social, são considerados, por certas heranças ideológicas neoliberais, como raras manifestações biológicas ou acidentes biográficos cujos encargos devem ser assumidos individualmente (ANDERSON \& HONNETH, 2011).

As vulnerabilidades humanas abarcariam, de acordo com uma certa vertente da gramática moral neoliberal, um espectro de condições e situações desabilitadoras e limitantes da agência dos sujeitos (subdesenvolvimento, pobreza abjeta, violação, injúria, fragilidade, deficiência, dependência, etc.), que impediriam a sua autorealização material, simbólica e política. Tal abordagem do conceito de vulnerabilidade autoriza que vários "dispositivos" [2] sociais, políticos e econômicos, produzidos tanto pelo Estado como outras instituições privadas, atuem para promover esquemas valorativos e avaliativos que designam pessoas vulneráveis tanto por uma suposta fragilidade física e racional, quanto por uma questionável habilidade para decidir e fazer escolhas de forma autônoma (FERRARESE, 2016; MACKENZIE, 2014). Assim sendo, nos parece de suma importância a investigação, análise e exposição dos múltiplos vetores de opressão e poder que controlam as vidas e mortes de sujeitas e sujeitos que, por serem mais vulneráveis que os demais, são injustamente injuriados, vitimizados e violentados. As vulnerabilidades, precariedades e violências que atravessam as vidas e mortes de sujeitas e sujeitos estigmatizados como "loucos", 
de um ponto de vista histórico, inquietam àqueles interessados numa genealogia das técnicas de governamentabilidade instauradas em concomitância com a emergência dos Estados modernos (FOUCAULT, 1980). A partir deste marco socio-histórico, podem ser identificados tanto o surgimento como a atualização de múltiplos dispositivos de ocultação e eliminação de corpos "extranormais" (como exílios, manicômios, castrações, suplícios fisiológicos e farmacológicos), com o intuito de banir do "organismo social" entidades tidas como avessas ou ameaçadoras ao projeto e processo de modernidade ocidental. Não obstante, principalmente a partir dos anos 1960, vetores de denúncia, contestação e luta coletiva, sobretudo performados pelos chamados movimentos sociais antimanicomiais, se apresentaram em oposição aos territórios asilares e manicomiais que encarceravam os corpos marcados pela "loucura" em suas grades e muralhas (AMARANTE, 1995; GOULART, 2010; BARBOSA et al., 2012; VENANCIO; TERESA, 2012).

Os movimentos sociais antimanicomiais no Brasil, ainda que em meio a tramas e vetores societários que insistem em eliminar do "sistema social" os corpos que atentam contra a manutenção de seus códigos e dispositivos, nos anunciam formas de existência, expressão e resistência que se esforçam em se tornar visíveis, tangíveis e reais. Seja na busca por superar suas precaridades ou no gesto de reconfigurar suas próprias vulnerabilidades enquanto potência de vida, a elaboração de estratégias e alianças produzidas entre aqueles em situação de sofrimento mental e outros agentes sociais e institucionais (familiares, militantes da luta antimanicomial, agentes que diretamente compõem os órgãos estatais, etc.) faz nascer outros códigos, sistemas e mundos possíveis. Tendo em vista tais evidências, acreditamos que o conceito de vulnerabilidade poderia ser ressignificado com relação à sua pretensa oposição à construção da autonomia e da resistência por sujeitos e vidas precárias. Seriam as vulnerabilidades dos sujeitos em situação de sofrimento mental, nos múltiplos contextos em que são relacionalmente experienciadas, vetores de limitação ou de impulsão de seus modos de autodeterminação política? Ainda, em relação ao referido coletivo, poderia o conceito de vulnerabilidade ser revisto como uma linguagem alternativa para expressão e denúncia de injúrias, danos e violências? 
O presente artigo procura apresentar uma reflexão em duas frentes acerca dos modos de existência, vulnerabilidades e resistências que atravessam as experiências, interações e processos comunicativos dos sujeitos em sofrimento mental no contexto de Belo Horizonte. Primeiramente, pretende-se apresentar de forma breve os conceitos de precaridedade e vulnerabilidade, tal como expressos por Judith Butler (2004, 2011) e outros autores, a fim de produzir suporte teórico para exposição de um mapeamento das interações e redes de relações que compõem algumas das vertentes do movimento de luta antimanicomial da cidade de Belo Horizonte. Num segundo momento, a partir de uma breve apresentação e análise de relatos, narrativas e depoimentos produzidos em trabalho empírico realizado junto à Associação dos Usuários de Saúde Mental de Minas Gerais (ASSUSAM-MG), nos propomos a refletir acerca de como o conceito de vulnerabilidade seria capaz de valorizar as singularidades que se manifestam nas redes de relações políticas que emergem pela ação relacional do referido coletivo. Não obstante, à luz da criatividade política e dos modos de resistência que se estabelecem a partir das práticas comunicacionais-deliberativas da ASSUSAM-MG, também esperamos verificar se, e em que medida, o conceito de vulnerabilidade nos é útil para evidenciar as potências político-expressivas infinitesimais que, interacionalmente, são condição da produção de um “comum” entre os membros que compõem a associação.

\section{Por uma "virada das vulnerabilidades"? Percursos, escolhas e cons- truções teórico-metodológicas}

O pensamento e a pesquisa sobre vulnerabilidades nos exigem refletir sobre atritos, disputas e incompatibilidades de preceitos ontológicos, epistemológicos, jurídicos e morais que fundamentam as sociedades ocidentais contemporâneas. Quando tais dispositivos são considerados em sua relação com a condição existencial inalienável da corporeidade humana, estes nos parecem insuficientes para lidar com o fato de que "a vida humana é condicionada pela vulnerabilidade" (MACKENZIE et al., 2014). O pressuposto acima é motivo para que um conjunto de autoras e autores nos proponham uma nova semântica política para a denúncia de injustiças e violências, a partir de um arcabouço teórico que tem sido rotulado como uma "virada das vulnerabilidades" (COLE, 2016). 
Nos recentes trabalhos de Judith Butler (2004, 2011, 2015 a e b), verificamos que a autora nos apresenta as noções de precariedade (precariouness) e vulnerabilidade das vidas humanas em referência a nossa inalienável condição corpórea; esta que nos exige produzir redes e cadeias de relações de suporte existencial para que vidas sejam possíveis de serem vividas. Não obstante, para Butler, a vulnerabilidade humana é considerada tanto em sua dimensão ontológica como social, tendo em vista que é mitigada, reconfigurada ou fomentada a partir de relações práticas e enquadramentos (frames) que, muitas das vezes, são definidores de vidas dignas de luto e outras cujo perecimento é naturalizado. Todavia, neste processo de definição qualitativa de vidas como dignas de luto ou não, ela afirma que arcabouços sócio-políticos dominantes não apenas tendem a reproduzir, mas também a legitimar uma falaciosa invulnerabilidade humana, tendo em vista que a vulnerabilidade, a precaridade (precarity) e a dependência são enquadradas como obstáculos à afirmação da autonomia e da autorealização individual. Tal busca pela invulnerabilidade, alimentada pela ideologia neoliberal, não pode ser menosprezada, afinal, ela sustenta, de um ponto de vista político, os projetos de fortalecimento de diversos Estados nacionais assentados sobre uma redistribuição global assimétrica da pobreza, da violência e da supressão de alguns coletivos em favor da proteção e fomento da vida de outros.

Conforme apontam Gilson (2011) e Goodin (1985), a defesa de uma ética das vulnerabilidades, em contraposição aos modelos políticos e econômicos neoliberais que a desconsideram como dimensão inerente e inescapável da existência humana, depende de um trabalho de ressignificação deste conceito; principalmente no que tange suas conotações negativas que enquadram os "sujeitos vulneráveis" como vítimas passivas. No pensamento destas e outras autoras, verificamos outras possibilidades de conceituar a vulnerabilidade para além de uma "constante possibilidade de dano ou injúria" como uma potência de "abertura para ser afetado e estar afetando por sua vez" (GILSON, 2011, p.310); sendo assim uma potência para criação e fomento relacional de múltiplas formas de existência. Contudo, neste empreendimeto de ressignificar o conceito de vulnerabilidade, constatamos um empenho teórico em se questionar e evidenciar os fatores e vetores sociais que contribuem para modular a vulnerabilidade ontoló- 
gica humana em opressão, violência e injustiça. Para Goodin (1985, p.191), por exemplo, é necessário que uma importante parte das mazelas que nos acometem (enquanto existências humanas corporificadas vulneráveis) não sejam naturalizadas, pois "qualquer dependência ou vulnerabilidade é indiscutivelmente criada, moldada ou sustentada, ao menos em parte, por arranjos sociais existentes”.

Segundo Mackenzie (2014), considerar a vulnerabilidade como dimensão inerente da ontologia humana, para que assim ressignifiquemos suas oportunidades e potencialidades, não implicaria um movimento de atenuação dos efeitos perversos que certos dispositivos e relações sociais produzem em "sujeitos mais vulneráveis que os demais" e que, segundo contextos e corporeidades marcadas pelo gênero, raça e saúde mental, operam de forma diferenciada. A partir de tal premissa, a proposição da autora é a de que, na defesa e construção de uma "ética das vulnerabilidades", sejam criadas formas de mapear, classificar e evidenciar a existência de contextos e arranjos sociais que contribuem para aprofundar as vulnerabilidades humanas de forma negativa. Assim, a construção de sistemas classificatórios e dispositivos de "medição" de vulnerabilidades, antes de serem endossados de antemão, devem ser ponderados a partir de seus possíveis efeitos e consequências no que tange a sua aplicação prática.

Mesmo que a chamada "virada da vulnerabilidades" nos ofereça importantes argumentos e evidências para um processo de ressignificação dos arranjos semânticos e semióticos que definem as vulnerabilidades como empecílios à construção da autonomia (sobretudo tendo em vista as "heranças normativas" de uma ideologia neoliberal presente no ocidente que atrela este conceito à pobreza abjeta, violação, injúria, fragilidade, deficiência e dependência), devemos nos questionar sobre os mecanismos sócio-políticos que exercem o poder de definir quem são e como devem ser tratados os sujeitos e sujeitas mais vulneráveis que os demais. A problematização referida, tal como realizada por Cole (2016, p.267268), nos permite levantar importantes questões acerca dos limites de adoção de uma "ética das vulnerabilidades" como linguagem alternativa para as teorias de justiça vigentes no ocidente: a) Quais seriam os princípios e agentes que legitimamente classificariam grupos e indivíduos como menos e mais vulneráveis? b) Uma taxonomia e hierarquização das vulnerabilidades não produziria por efeito 
novos estigmas e exclusões, ao mesmo tempo que novos sistemas de regulação, controle e poder de cunho paternalista? c) Será que as políticas e dispositivos que buscam proteger, ignorar ou eliminar os vulneráveis existem, primariamente, devido a uma falha dos agentes do Estado em reconhecer nossa condição compartilhada de vulnerabilidade no que abarca tanto a constante possibilidade de injúria e dano como de uma abertura positiva de ser afetado e afetar em troca? d) Por fim, não seria o desprezo para com o conceito de vítima e vitimização resquício de uma ideologia liberal que sobrevaloriza o conceito de agência e que tornam patológicos o sofrimento, o trauma e a dependência?

Exposta a situação probleática acima, procuraremos verificar, neste artigo, como as potencialidades do arcabouço teórico "virada das vulnerabilidades" se apresentam quando examinadas à luz da experiência interacional de um coletivo que se agrega enquanto vertente da luta antimanicomial no Brasil, a saber, a Associação dos Usuários do Sistema de Saúde Mental de Minas Gerais (ASSUSAM-MG) [3].

Nosso primeiro contato com um dos membros da Associação dos Usuários de Saúde Mental de Minas Gerais (ASSUSAM-MG) se deu nas dependências da Universidade Federal de Minas Gerais (UFMG), em meados de 2015, quando do evento "Semana de Saúde Mental”. Nesta ocasião, foram convidados diversos usuários dos serviços de atendimento à saúde mental do SUS de Belo Horizonte para que estes compartilhassem, no território acadêmico, seus saberes, depoimentos e histórias de vida enquanto sujeitos e sujeitas que experienciam e resistem às mazelas do sofrimento mental. Ao participar do evento, fomos surpreendidos com uma apresentação de um grupo teatral, formado por alguns destes usuários, o “Nau dos Loucos”. Ao final da apresentação, procuramos um dos integrantes do grupo a fim de melhor compreender as condições de formação e execução de tal trabalho. Nesta interação, nos foi exposto que o grupo "Nau dos Loucos" é formado principalmente por membros da ASSUSAM-MG que semanalmente se reunem nas dependências do Conselho Regional de Psicologia de Minas Gerais (CRP-MG) não apenas para produzir arte, mas para compartilhar, refletir, deliberar e reivindicar melhorias nas condições dos serviços de saúde mental oferecidos pelo Estado. A partir desta abertura, participamos de doze reu- 
niões na ASSUSAM-MG, sendo três ainda em 2015 e nove durante o ano de 2016. Cabe ressaltar que, nos anos de 2017 e 2018, nossa pesquisa se voltou para outros grupos que fazem parte das redes de luta antimanicomial de Belo Horizonte, como o Fórum Mineiro de Saúde Mental; situação esta que nos permitiu ampliar nosso aprendizado sobre a agência político-deliberativa de vários dos importantes protagonistantes protagonistas da luta antimanicomial assim como a situação das sujeitas e sujeitos que experienciam as mazelas do sofrimento mental.

No que tange os dados de pesquisa produzidos e mobilizados neste artigo (como descrições, narrativas, depoimentos, acontecimentos e afecções), ressaltamos nossa deliberada seleção e recorte não exaustivo da multiplicidade de registros produzidos em situação de observação participante nos contextos de deliberação da ASSUSAM-MG. Neste sentido, o material empírico aqui exposto não têm a pretensão de representar a múltipla e complexa realidade dos sujeitos e sujeitas em sofrimento mental; menos ainda almejam nos posicionar enquanto críticos ou prolocutores do movimento de luta antimanicomial. Ainda, esperamos que nosso empreendimento não limite estes dados interacionais simplesmente como suporte para ilustração teórica. Pelo contrário. O objetivo desta pesquisa, ainda que vulnerável e precário por conta de nossas limitações e assimetrias enquanto pesquisadores, é evidenciar, atualizar e questionar a própria teoria à luz da perspectiva e experiência de sujeitos e sujeitas que, menos ou mais atravessados cotidianamente por complexos sistemas estigmatizantes e relações de poder, nos anunciam outros mundos possíveis a partir de um agenciamento coletivo de resistência e criatividade política.

\section{Mapeamento de redes e relações de vulnerabilidade, poder e resis- tência política: nas trilhas da ASSUSAM-MG}

Buscando compreender como a ação política dos sujeitos em sofrimento mental é atravessada por complexas vulnerabilidades, consideramos como um primeiro caminho possível de reflexão o mapeamento de alguns dos fatores que mobilizam, influenciam e/ou exigem que os membros da ASSUSAM-MG produzam os seus acontecimentos interacionais deliberativos, redes de relações e políticas de aliança e oposição. Neste movimento, também almejamos verificar em 
que sentido as noções de vulnerabilidade e precariedade (precariouness) apresentados anteriormente se adequam perante alguns dos traços que compõem a experiência política, formas de agenciamento e expressão interacional tal como registrados em trabalho de observação participante no contexto ASSUSAM-MG.

Os acontecimentos de deliberação que se estabelecem no contexto da ASSUSAM-MG são vulneráveis. Por um lado, como nos sugerem Anderson e Honneth (2011), as relações sociais que são potencialmente fonte para construção relacional de auto respeito, autoconfiança e autoestima, quando isentas de mecanismos de reconhecimento intersubjetivo, podem produzir efeitos danosos. Por outro, processos interacionais que visam a produção de luta por reconhecimento e justiça são também vulneráveis por outros importantes vetores, sendo estes menos ou mais intensificados pelas próprias biografias dos sujeitos e sujeitas que compõem os grupos e redes em questão. Tal situação se evidencia, em primeiro plano, quando considerarmos os recursos materiais que, mais explicitamente, são suporte concreto para as corporeidades que se reúnem enquanto ASSUSAM-MG.

Os contextos de deliberação produzidos pelos membros da ASSUSAM-MG, por dependerem necessariamente da presença corporificada de seus membros, nos apontam importantes indícios que nos levam a compreender como vulnerabilidade ontológica destes corpos necessita ser atenuada e/ou superada para estes possam se agregar enquanto movimento político. Localizado na região central de Belo Horizonte, o Conselho Regional de Psicologia de Minas Gerais (CRP-MG) cede seu auditório para a realização dos encontros quinzenais da ASSUSAM-MG; encontros estes que, até o ano de 2017, ocorriam nas segundasfeiras, às 19 horas, com duração de aproximadamente uma hora e meia. Além de todo o aparato mobiliário, verificamos em diversas ocasiões que o CRP-MG disponibiliza lanches aos presentes, computador com impressora e inclusive seus funcionários - que atuam no agendamento de reuniões e providenciam a reserva do auditório - como suporte material para a constituição da própria associação. Não obstante, tal aliança ainda não é suficiente para garantir os acontecimentos deliberativos da ASSUSAM-MG. Como verificamos em diversos encontros, a própria capacidade de se deslocar na cidade e chegar ao CRP-MG é uma questão 
problemática. Em diversas situações interacionais testemunhadas, nos deparamos com questionamentos dirigidos à tesoureira da associação sobre o processo de repasse de vales transporte para que os sujeitos e sujeitas em situação de sofrimento mental participem e produzam seus encontros deliberativos. Mas por qual motivo os recursos descritos acima, que à primeira vista nos parecem tão básicos, são fundamentais para que os acontecimentos da ASSUSAM-MG possam se efetuar na prática?

A questão acima levantada poderia ser melhor elucidada quando nos voltamos para as vulnerabilidades que atravessam as corporeidades dos sujeitos em sofrimento mental que constituem a associação em questão. Seguramente, a maior parte dos sujeitos e sujeitas de nossa pesquisa se encontram interseccionadas e atravessadas por situações de dependência material que, quando são mitigadas, o são por suas famílias, programas de distribuição de renda do Estado e/ou outras atividades pouco remuneradas que estes exercem como artistas e artesãos. Mesmo para os que ainda possuem meios outros de auferir renda, a impossibilidade de conseguir empregos com maior probabilidade de expressivo reconhecimento econômico não é apenas uma questão de escolha, mas de impossibilidade socialmente gerada. Tal situação de vulnerabilidade material torna-se uma ameaça à existência destes sujeitos, por exemplo, com relação ao seu direito fundamental de moradia, tendo em vista que muitos deles dependem de residências ou instalações governamentais para evitar a situação de rua [4]. Tais características nos apontam uma lastimável relação que se estabelece entre a condição de sofrimento mental e a precariedade socioeconômica. Do ponto de vista do membro da ASSUSAM-MG, Humberto [5], senhor de aproximadamente 50 anos, branco, aposentado e que mora com sua família, sua vulnerabilidade possui causas claramente sociais:

Fiz curso técnico em mecânica antes de começar a ter crises, tomar medicação e ser internado. Antes eu trabalhava. Depois, ninguém mais me contratou! Tenho certeza que estou bom para trabalhar. Mas como a empresa vai ter certeza disso? Agora vivo da minha aposentadoria e na casa da minha irmã...não é fácil depender dos outros, mas o que vou fazer? (Humberto, relato concedido aos autores em agosto de 2016)

O depoimento acima apresentado nos exige refletir sobre uma complexa questão que surge como efeito do estigma generalizado atribuído ao so- 
frimento mental pelos sistemas e dispositivos simbólicos vigentes no contexto brasileiro. A precariedade do sofrimento mental tende a ser enquadrada, como nos aponta o relato acima, como um fator destituidor de agência e capacidade laboral-intelectiva mesmo que, do ponto de vista dos próprios sujeitos em sofrimento mental, tal enquadramento não corresponda às suas aptidões práticas. Por outro lado, na busca pela atenuação de suas precariedades materiais, a partir do acesso a políticas sociais promovidas pelo Estado, verifica-se uma perversa necessidade de adequação a regras de expressão e exposição do sofrimento mental enquanto uma condição inerentemente incapacitante. Conforme nos indicam relatos testemunhados no contexto ASSUSAM-MG sobre a questão acima referida, quanto mais deterioradas e vitimizantes forem a apresentação de narrativas e corporeidades perante a alguns agentes do Estado encarregados, mais aptos os sujeitos em sofrimento mental se encontrariam para receber a assistência e proteção que deveria lhes ser dispensada por direito. Assim sendo, nos parece que a definição da vulnerabilidade do sofrimento mental, que varia segundo interações sociais contextuais, produz consequências concretas não apenas na vida material destes sujeitos, mas também condiciona sua performance e auto-estima corpórea no cotidiano.

Conforme exposição anterior, verificamos, ainda que parcialmente, como algumas das vulnerabilidades e precariedades dos sujeitos em sofrimento mental estão para além de sua condição fisiológica. Como nos aponta Fassin (2006, 2009, 2015), a existência social de doenças mentais precisa de uma configuração semântica que a torne compreensível, naturalizada e "tratável" a fim de ser reificada ou contestada. Assim, o sofrimento mental não se restringe às experiências individuais dos sujeitos, mas tem origens sociais (pobreza, violência, estigmatização, construção de quadros morais de julgamento e afetos) que necessitam ser evidenciadas para que assim sejam contestadas. O olhar que paira sobre o sofrimento mental geralmente toma os indivíduos como vítimas, diante das quais um sentimento de empatia e um imperativo moral de solidariedade tende a devolvê-las à invisibilidade, ao silêncio e ao ostracismo (RENAULT, 2004).

As características das relações estabelecidas pelos sujeitos em sofrimento mental com agentes e instituições do Estado, que oscilam entre proteção, 
dependência e opressão, nos parecem mais evidentes quando verificamos os relatos desses sujeitos em relação à sua experiência para com os Centros de Convivência e Centros de Referência em Saúde Mental (CERSAM) do SUS em Belo Horizonte. Por um lado, os Centros de Convivência são territórios que permitem acolhimento, convívio, alimentação, socialização e, inclusive, capacitação artística e profissional das pessoas que lá frequentam. Por outro lado, como expresso em diversas queixas e reclamações de seus usuários no contexto ASSUSAM-MG, as instituições acima referidas são também recorrentes territórios de dissensos, conflitos e danos. Seja pelos controles de horários, usos do espaço, agendas de atividades e oficinas, seja pela performance de funcionários do Estado que mobilizam uma fachada de indiferença ou desrespeito interacional para com os usuários das instituições supracitadas, a qualidade destas relações faz variar sua potência de operar em favor ou em oposição às vidas dos sujeitos em sofrimento mental

A questão acima exposta torna-se ainda mais complexa no caso dos CERSAMs. Mesmo que este seja um dispositivo que publicamente se expressa como avesso à lógica manicomial de tratamento da "loucura", narrativas que atestam sobre investimentos opressivos contra corpos em sofrimento mental são recorrentemente elaboradas e apresentadas no contexto ASSUSAM-MG. Nas palavras de Elisa - mulher negra, desempregada, mora com a família e de aproximadamente 25 anos - e Cândido - homem, artista em situação de rua, e de aproximadamente 60 anos - verificamos não apenas a dificuldade, mas também a impossibilidade de se separar a vulnerabilidade do sujeito em sofrimento mental que decorre de sua condição biológica da que é experienciada em forma de violência socialmente produzida por interações sociais pautadas por quadros simbólicos estigmatizantes:

Quando entrei em crise me levaram (família) para o CERSAM. Eu estava fora de mim, muito irritada, quebrando tudo na minha casa. Cheguei no CERSAM em crise e não queria ficar lá não. Quando uma enfermeira me amarrou na cama para me dar injeção, senti que ia explodir... porque estavam me amarrando? Depois da injeção, não vi mais nada, blackout. Claro que acordei mais calma, depois de dormir o outro dia inteiro! Mas talvez não tinha jeito naquela hora, eu estava muito fora de mim...tava quebrando tudo em casa, logo eu! Mas ficar lá no CERSAM não era bom...Pelo menos quando me deram alta e fui para o Centro 
de Convivência que eu comecei a melhorar. Pra mim foram as oficinas de música e as pessoas de lá; a maioria é muito gente boa, preocupada com a gente, conversam, quer saber como a gente tá. (Elisa, entrevista concedida aos autores em maio de 2018)

Estou a ver navios! Não sei o que está acontecendo comigo. Faço tratamento há mais de 18 anos! Tenho esquizofrenia, amnésia, transtorno bipolar. Estou muito sozinho! Moro na rua, não tenho família. Estou cada vez mais descrente da vida, não aguento mais. (...) Não consigo mais viver desse jeito, estou muito sozinho porque as pessoas não dão ouvidos para um doente igual a mim. Já não como há algum tempo e no centro de saúde que frequento a situação também não está boa. A comida é muito ruim. Lá não têm companheiros. Penso que vou morrer! (Cândido, relato concedido aos autores em agosto de 2016)

A nosso ver, é justamente pela possibilidade de se agregarem e expressarem a si mesmos coletivamente que as sujeitas e sujeitos da ASSUSAM-MG promovem fraturas, ainda que infinitesimais, nos quadros que definem e limitam suas capacidades e modos de existência. Tal afirmativa se sustenta, por exemplo, quando verificamos a importância das alianças produzidas entre os membros da ASSUSAM-MG com os coletivos de economia solidária Suricato [6] e grupos de arte, como o teatral "Sapos e Afogados”. A partir das interações estabelecidas nos grupos acima referidos, sujeitos como Romarinho - aposentado, artista, com idade acima de 50 anos e que já fora internado em hospital psiquiátrico - podem ter a possibilidade de, para além de angariar recursos econômicos, ressignificarem seu status e auto relação prática consigo e com os outros a partir da ampliação de suas relações, articulações e alianças:

\footnotetext{
"O teatro, a arte é minha vida! Eu que já fiquei preso numa cama de hospital, sem poder fazer nada, não posso mais viver sem arte. Lá eu conheci minha companheira, fiz vários amigos. Além disso, muitas vezes que apresentamos ganhamos cachê, o que eu acho muito importante porque o teatro e arte são um trabalho." (Romarinho, entrevista concedida aos autores em junho de 2016)
}

O breve mapeamento de redes, relações e relatos aqui apresentamos com referência à experiência deliberativa dos membros da ASSUSAM-MG nos demonstram que, por um lado, as noções teóricas de vulnerabilidade/precariedade são parcialmente satisfatórias no que tange uma análise dos aparentes paradoxos que se estabelecem nos processos de construção do movimento social 
antimanicomial. Lutas políticas minoritárias, como processos agonísticos em si, são amplamente vulneráveis em sua composição; situação esta que possibilita/ exige tanto a construção de alianças improváveis e com efeitos imprevistos no que tange a potencialização das vidas de seus protagonistas. Por outro lado, verifica-se que o conceito de vulnerabilidade, no mínimo, tende a produzir um certo "eufemismo" para com os fluxos, mecanismos e relações de poder que não apenas contribuem, mas perpetuam atos de violência para com as corporeidades em situação de sofrimento mental. Se ainda verificamos no contexto brasileiro a existência de múltiplos corpos ocultados, sequestrados, medicalizados, docilizados e/ou violentados por estigmas sociais, marcados a priori pelo gênero, raça, etnicidade e sofrimento mental, concluímos que o conceito de vulnerabilidade e seus rótulos derivados, como por exemplo "sujeitos vulneráveis", carecem da "urgência" política de uma adequada nomeação de danos, injustiças e violências. Talvez, como nos sugere Cole (2016), a noção de "vítima" possa nos ofertar tal qualidade política; ainda que também necessite de posteriores ressignificações no que tange à sua oposição para com as noções de agência e autonomia. É imperativo que também nos perguntarmos de que maneiras podem surgir, no interior da máquina de produção de subjetividades, novas formas de inventar conjuntamente valorizações e autovalorizações (BUTLER 2015a e b; RENAULT, 2004; FASSIN, 2015).

\section{Semioses vulneráveis e dimensões expressivas de resistência: a agência das "vítimas" do sofrimento mental e suas "biopotências" infinitesimais}

Ao visitarmos o pensamento de Hardt e Negri (2000), constatamos que estes autores não vão nos interrogar apenas acerca do poder e de suas formas de manifestação, mas sobre a vida e suas potencialidades. Ao reivindicarem que a noção mesma de vida deixe de ser ser reduzida à sua definição biológica, os autores nos propõem também compreendê-la como uma experimentação permanente, fomentada por formas menores de articulação que produzem outras subjetividades no campo das resistências. Inspirado pelas considerações de Hardt e Negri, o filósofo Pelbart (2002, p.42) ressalta que "talvez o desafio atual seja intensificar esses estalos e rachaduras a partir da 'biopotência' da multidão”; 
criando condições para que, ao lado da dominação, emerja a insubordinação: "é lá onde as pessoas sofrem, ali onde elas são as mais pobres e as mais exploradas; ali onde as linguagens e os sentidos estão mais separados de qualquer poder de ação é onde, no entanto, existe a vida e não a morte" (idem).

Assim exposto, pretendemos, nesta parte do artigo, produzir um mapeamento de vetores e traços de "biopotência", tal como identificamos em nossa experiência interacional no contexto ASSUSAM-MG. Entretanto, para não corrermos o risco de sobrecodificar práticas e interações dos menos ou mais vulneráveis/vítimas que experienciam o sofrimento mental, não poderemos deixar de considerar que a própria "biopotência", por ser produzida por entidades corporificadas, se manifesta dentro de certos limites. Assim sendo, nos voltaremos, agora, para o próprio processo deliberativo da ASSUSAM-MG a fim de verificar como a linguagem e a comunicação são condições necessárias para a produção de resistência política deste coletivo e, quem sabe, de sua própria "biopotência".

Como instituição ancorada em uma sintaxe normativa democrática, certas regras, ritos e estruturas são mobilizadas para garantir a eficiência, pluralidade de participação e ordenamento dos encontros da ASSUSAM-MG. Em todos os encontros em que um de nós esteve presente, a deliberação se iniciou com a leitura da ata da reunião anterior e, na sequência, com informações e repasses sobre as questões que se encontram em aberto. Este movimento de definição da situação de deliberação é geralmente realizado pelo presidente ou vice-presidente eleito dentre os próprios membros da ASSUSAM-MG. Num segundo momento do processo deliberativo em questão, são recebidas inscrições daqueles que gostariam de falar e expor as suas situações cotidianas, de forma a se estabelecer uma sequência de falas. Tal estrutura, ou orientação normativa, nos demonstra que os próprios membros deste grupo desejam se organizar, a partir de critérios e requisitos de participação, plenamente cientes da importância de os proteger das assimetrias que atravessam a construção comunicacional de entendimento e dissenso. Não obstante, a racionalidade comunicativa, que este coletivo nos apresenta, ao espelhar procedimentos usualmente adotados em outros espaços institucionalizados de deliberação, não nos chama atenção pela suas normas, mas pelo modo de acomodação das afecções produzidas pelas corporeidades presentes. 
No contexto deliberativo ASSUSAM-MG, as exclusões, constrangimentos e impedimentos interacionais, assim como as resistências, projetos e conquistas relacionais encontram espaço, tempo e matéria para reverberarem. Para aqueles que desejam realizar repasses, convites ou compartilhar sobre o andamento de seus projetos existenciais e políticos, como os artistas que integram os grupos teatrais "Nau dos Loucos" e "Sapos e Afogados", estes têm a oportunidade de se inscreverem para a lista de fala e se exporem perante aos demais. Também, para aqueles que possuem denúncias, descontentamentos ou incertezas para com os dispositivos do sistema de saúde mental do SUS, a possibilidade de trazer à tona seus sentimentos, ressignificar ou intensificar os seus pontos de vista e, principalmente, traçar estratégias coletivas para a superação de suas impossibilidades, encontram uma janela para vislumbrar outros mundos possíveis.

Ao expressar pontos de vista individuais sobre as questões acima expostas e outras que almejam dissenso e/ou entendimento, muitos compartilham narrativas e episódios da vida cotidiana; outros ficam em seus lugares e aguardam o início dos encontros. Estes são momentos privilegiados em que sujeitos e sujeitas em sofrimento mental, evitadas, invisibilizadas e rejeitadas que em em tantos outros campos sociais, se tocam, se cumprimentam, se abraçam e se afetam. $\mathrm{O}$ outro, distante ou incógnito, pode se tornar reconhecido. Seja pela indicação de outros centros de saúde mais acolhedores e bem equipados, convite para participar de protestos, grupos de arte, instituiões de economia solidária ou até mesmo grupo de orações, novos caminhos são desenhados a partir de uma interação em que códigos, corporeidades e linguagens emergem sem se limitar a citações, teorias e encadeamentos linguísticos que atendem a uma certa lógica hegemônica. Mas porque tal processo é facilitado neste contexto?

Propomos, aqui, que é justamente pela possibilidade de abertura para se expressar, a partir da própria linguagem de quem experiencia o sofrimento mental, que um "transbordar" da pretensa parede que define quando um modo de expressão é racional ou irracional, autonômo ou vunerável, ocorre. Seja pelas intensas e inesperadas expressões de fúria e/ou alegria, de lágrimas e/ou abraços, de inquietação e/ou de silêncio - estes que não são considerados, a priori, como inválidos neste contexto - que formas de expressão da vulnerabilidade e da autonomia, da violência 
e da conquista, da injúria e da resistência, que a produção de um "comum" se estabelece. E é neste sentido que consideramos esta força poética da linguagem cotidiana, mediada por um contexto de acolhimento e hospitalidade, que uma "biopotência infinitesimal" emerge e se atualiza pela possibilidade de borrar as dicotomias mentecorpo, racional-irracional, vulnerabilidade-autonomia, vitimização-agência política.

\section{Considerações finais}

A força poética do cotidiano e de seus objetos reside também em sua possibilidade de dar forma ao comum. Este acontecimento, como ressalta Pelbart (2002), nos oferece uma possibilidade de encontro, de fraternidade precária, de empatia, sem que o processo interacional que lhe é causa se transforme em algo instituído, em instituição. Para Pelbart, as "subjetividades esquizas" dos supostos "loucos" ocupam um território ao mesmo tempo em que o desmancham. Nesse sentido, dificilmente elas entram em confronto direto com aquilo que recusam, não aceitam a dialética da oposição (pois sabem estar submetidas de antemão ao campo do adversário). Por isso, elas “deslizam, escorregam, recusam o jogo ou subvertem-lhe o sentido, corroem o próprio campo e, assim, resistem às injunções dominantes.” (PELBART, 2002, p.34). Dessa maneira, os “esquizos” produzem cenas-experimentações nas quais "agenciamentos biopotentes" transformam as coordenadas de enunciação de suas vidas.

Partindo das proposições acima, argumentamos que é justamente no bojo dessa condição precária que o trabalho da criação política do "eu” e do "nós" requer a modelagem de um comum. O "comum” é, ao mesmo tempo, o que une e o que separa, o consenso e o dissenso, a rendição e a resistência. Ele pode ser descrito como a "dimensão intervalar, na qual nos remetemos uns aos outros e a nós mesmos", configurando-se, por meio da "instituição de intervalos que ligam sujeitos e realidades, sem englobá-los nem integrá-los” (TASSIN, 1992, p.33). Além disso, Silva (2011) aponta o "comum”, como resultado de um intervalo, como um espaço vazio, no qual damos forma ao "entre nós” e à reciprocidade, um espaço de escuta e de acolhimento de outras temporalidades e existências, sem que, contudo, esteja isento das distinções e das distâncias. 
Eis aqui uma proposição que nos parece central para que possamos apontar um possível caminho para a resistência à vulnerabilidade, precariedade, injustiça e a violência: o "comum" de uma comunidade diz do "aparecer" dos sujeitos e de seus rostos na esfera de visibilidade pública como interlocutores dignos de respeito e estima, como sujeitos poéticos, cuja potência da vida pode ser renovada - ainda que de forma vulnerável e precária.

\section{Notas}

[1] Utilizamos o termo "governamentalidade" em correspondência ao conceito de Foucault (gouvernementalité), que se refere ao controle, gerenciamento, condução e governo coletivo da vida humana.

[2] Consideramos aqui que o termo "dispositivo" (FOUCAULT, [1977], 1994) pode tanto fazer referência a arranjos estratégicos de imposição de poder dentro da construção de formas biopolíticas de governo, quanto a arranjos relacionais e tentativos de criação de formas experimentais de resposta a demandas urgentes por transformação. Assim, a experimentação por meio da montagem de dispositivos requer novos arranjos entre corpos, fazeres, dizeres e gestos, os quais podem dar origem a "dispositivos interacionais" (BRAGA, 2018), que nascem dessa urgência de elaborar (com grande responsabilidade) uma resposta, a partir de estratégias diversas, às imposições de poder e ao autoritarismo.

[3] A ASSUSAM-MG é uma instituição fundada em 1994, a partir de uma articulação conjunta entre profissionais e usuários do Sistema de Saúde Pública do SUS, principalmente no que tange à saúde mental. Os objetivos da instituição podem ser consultados em <http:// www.crpmg.org.br/CRP2/File/Asussam\%20-\%20diretrizes.JPG >. Acesso em: 4 ago. 2018.

[4] Exibir a precariedade, relatá-la em narrativas de vulnerabilidade, como destituidora de agência, são as regras por trás de formulários padronizados e atendimentos patologizantes, em uma espécie de exigência, a priori, para o acesso a políticas sociais. Quanto mais deteriorados e vitimizados forem os corpos e suas condições de subsistência, mais aptos parecem estar os sujeitos a receberem a "caridade" ou o "castigo" do Estado (a legitimidade do corpo precário é chamada por Fassin de biolegitimidade), segundo critérios normativo-afetivos, que julgam a partir da fronteira entre mérito e compaixão (FASSIN, 2009; 2015).

[5] Os nomes utilizados neste artigo para se referir aos sujeitos e sujeitas de pesquisa são fictícios, tendo em vista o atendimento à solicitação de preservação de seu anonimato.

[6] Associação de trabalho e economia solidária que emprega usuárias e usuários da rede de saúde mental.

\section{Referências}

AMARANTE, P. Loucos pela vida: a trajetória da reforma psiquiátrica na Brasil. Rio de Janeiro: Fiocruz, 1995. 
ANDERSON, J.; HONNETH, A. Vulnerabilidade, Reconhecimento e Justiça. Cadernos de Filosofia Alemã: Crítica e Modernidade, n. 17, p. 81-112, 2011. Disponível em: < http://www.revistas.usp.br/filosofiaalema/article/view/64839>. Acesso em: 4 ago. 2018.

BARBOSA, G. C.; COSTA, T. G.; MORENO, V. Movimento da luta antimanicomial: trajetória, avanços e desafios. Cad. Bras. Saúde Mental, v. 4, n. 8, p. 45-50, 2012. Disponível em: < http://incubadora.periodicos.ufsc.br/index.php/cbsm/ article/view/2017>. Acesso em: 4 ago. 2018.

BRAGA, José Luiz. Interagindo com Foucault. Os arranjos disposicionais e a Comunicação. In: XXVII Encontro Anual da Compós, 2018, Belo Horizonte (MG). Anais... Belo Horizonte (MG): Compós, 2018. Disponível em: <http://www. compos.org.br/data/arquivos 2018/trabalhos arquivo TUYEGGUY9oCMV$\begin{array}{lllllllll}19 N H P B 9 & 27 & 6300 & 08 & 02 & 2018 & 10 & 58 & \text { 00.pdf }>\text {. Acesso em: } 4 \text { ago. } 2018 .\end{array}$

BUTLER, J. Precarious Life. London: Verso, 2004.

- Quadros de guerra: quando a vida é passível de luto? Rio de Janeiro: Civilização Brasileira, 2015a.

. Notes toward a performative theory of assembly. Cambridge: Harvard University Press, 2015b.

COLE, A. All of us are vulnerable, but some are more vulnerable than others: the political ambiguity of vulnerability studies, an ambivalent critique. Critical $\mathrm{Ho}-$ rizons, v.17, n.2, 2016, p.260-277. Disponível em : < https://bit.ly/2n17CUR $>$. Acesso em : 4 ago. 2018.

FASSIN, D. Souffrir par le social, gouverner par l'écoute: une configuration sémantique de l'action publique. Politix, v.19, n.73, p.37-157. 2006. Disponível em: $<$ https://bit.ly/2Aw3dmv>. Acesso em : 4 ago. 2018.

. Another politics of life is possible. Theory, culture \& society, v.26, n.5, p.44-60, 2009. Disponível em: < https://bit.ly/2O49APZ>. Acesso em : 4 ago. 2018.

2015.

. At the Heart of the State: the moral world of institutions. Pluto Press,

FERRARESE, Estelle. Vulnerability: a concept with which to undo the world as it is? Critical Horizons, v.17, n.2, 2016, p.149-159. Disponível em: < https://bit. ly/2KfMXWq >. Acesso em : 4 ago. 2018.

FOUCAULT, M. Poder de morte e direito sobre a vida. In: História da sexualidade: a vontade de saber. Rio de Janeiro: Graal, 1980. v. 1, p. 127-152.

. Le jeu de Michel Foucault. Entrevista dada à revista Ornicar. Dits et Écrits, v.3 [1977], 1994, p.194-228. Disponível em: < https://bit.ly/2LJSlgN>. Acesso em : 4 ago. 2018.

GILSON, E. The Ethics of Vulnerability: A Feminist Analysis of Social Life and 
Practice. New York: Routledge, 2014.

HARDT, M.; NEGRI, A. La production biopolitique. Multitudes, v. 1, n. 1, p. 1628, 2000. Disponível em : < https://bit.ly/2mZo8EK>. Acesso em : 4 ago. 2018.

HOFFMASTER, B. What does vulnerability mean. Hastings Center Report, v. 36, n. 2, p. 38-45, 2006. Disponível em: <https://bit.ly/2LK5oIn>. Acesso em : 4 ago. 2018.

MACKENZIE, C. The Importance of Relational Autonomy and Capabilities for an Ethics of Vulnerability. In: MACKENZIE, C.; ROGERS, W.; DODDS, S. (Eds.). Vulnerability New Essays in Ethics and Feminist Philosophy. New York: Oxford University Press, 2014, p.33-59.

PELBART, P. P. Poder sobre a vida, potência da vida. Lugar Comum, n.17, p.3343, 2002. Disponível em: < https://bit.ly/2LTPaeP>. Acesso em : 4 ago. 2018.

RENAULT, E. L'expérience de l'injustice: reconnaissance et clinique de l'injustice. Paris: La Découverte, 2004.

SILVA, R. Apresentação (elegia do comum). In: SILVA, R.; NAZARÉ, L. (Orgs.). A república por vir. Arte, Política e Pensamento para o século XXI. Lisboa: Fundação Calouste Gulbenkian, 2011, p.11-37.

TASSIN, E. Espace commun ou espace public ? L'antagonisme de la communauté et de la publicité, Hermès, v.10, p.23-37, 1992. Disponível em : < https://bit. ly/2LTPaeP>. Acesso em : 4 ago. 2018. 